\title{
Multiple imputation is better than KDIGO guidelines to estimate unknown baseline renal function
}

\author{
Mathieu Jamme and Guillaume Geri \\ See related research by Wang et al., http://ccforum.biomedcentral.com/articles/10.1186/s13054-015-1085-4.
}

Recently in Critical Care, we read with great interest the study by Wang et al. [1], who assessed the fluid balance impact on acute kidney injury (AKI) in critically ill patients. Fluid overload was independently associated with the outcome in this large prospective Chinese cohort.

As recommended by international KDIGO (Kidney Disease: Improving Global Outcomes) guidelines, AKI was defined as an increase of serum creatinine $(\mathrm{SCr})$ within 48 hours from baseline $\mathrm{SCr}$ or urine output or both [2]. For patients without a known baseline SCr, the same KDIGO guidelines recommend the use of a hypothetical value of $\mathrm{SCr}$ assuming a "normal" estimate glomerular filtration rate (eGFR) of $75 \mathrm{ml} / \mathrm{min}$ per $1.73 \mathrm{~m}^{2}$ [3]. This "simple imputation" could be an attractive method but tends to distort the distribution of variables and the association between them, which can lead to a biased estimation [4].

The multiple imputation method has been proposed and nowadays is considered one of the best methods for analyzing data sets with missing data values. Indeed, this method adequately estimates the unknown parameters whereas biases have been found with single imputation. Unfortunately, this method is not frequently used in the intensive care unit (ICU) literature. However, in the specific case of unknown baseline SCr in AKI study, some authors had observed that the multiple imputation method had a lower rate of AKI misclassification than the "eGFR 75 simple imputation" [5]. We hope Wang et al. will comment on their choice of imputation method.

\section{Authors' response}

Na Wang, Li Jiang and Xiuming Xi

We read with great interest the letter from Mattieu Jamme and Guillaume Geri and agree that the multiple imputation method is one of the best methods for analyzing data sets with missing data values.

In our research, the AKI severity was classified according to the KDIGO guidelines [2] because an article published before we found the KDIGO criteria identified more patients as AKI than RIFLE (Risk, Injury, Failure, Loss of kidney function, and End-stage kidney disease) and AKIN (Acute Kidney Injury Network) did [6]. In that article, missing baseline $\mathrm{SCr}$ values were estimated by using the Modification of Diet in Renal Disease (MDRD) Study equation assuming that baseline eGFR is

\footnotetext{
* Correspondence: mathieu.jamme@aphp.fr

Intensive Care Unit, Cochin Hospital, Assistance Publique Hôpitaux de Paris, 27 rue du Faubourg Saint Jacques, 75014 Paris, France
}

$75 \mathrm{ml} / \mathrm{min}$ per $1.73 \mathrm{~m}^{2}$; we know that this "simple imputation" could lead to a biased estimation. But the purpose of our study was not to compare which method can more accurately estimate the baseline $\mathrm{SCr}$, and we do not know whether the multiple imputation method will produce different conclusions, but we are very willing to try it.

Some authors had observed that the multiple imputation method had a lower rate of AKI misclassification in comparison with the "eGFR 75 simple imputation" [5]. In this research, the subjects were inpatients and, compared with ICU patients, had different homogeneity. If this method is used to evaluate the population of critically ill patients, we do not know what indicators should be included in the multiple imputation model and whether the full multiple imputation in the study of Siew 
ED et al (sex, race, dialysis, admission service and so on) are sufficient and appropriate for ICU patients so far, no studies give us enough information. Whether multiple imputation is applicable to critically ill patients needs further confirmation.

The quality of multiple imputation depends on the judgment of the data missing mechanism, the setting of the filling model, and selection of filling times. The missing data mechanism is the process that generates missing values, which generally fall into three categories: missing completely at random, missing at random, and missing not at random. Multiple imputation generally assumes that the data is at least missing at random [7].We can establish the rationality only based on the general theory of missing values; we cannot combine the specific circumstances of the data to accurately determine whether the multiple imputation results in our research is really more reasonable. Multiple imputation is a difficult thing for inexperienced researchers, so we did not choose this method. But we are also very grateful for the valuable comments from Jamme and Geri and are preparing to compare the ability of multiple imputation approaches with eGFR 75 in estimating actual baseline creatinine values in critically ill patients.

\section{Abbreviations}

AKI, acute kidney injury; eGFR, estimate glomerular filtration rate; ICU, intensive care unit; KDIGO, Kidney Disease Improving Global Outcome; $\mathrm{SCr}$, serum creatinine

\section{Authors' contributions}

MJ drafted the manuscript. GG helped to draft the manuscript. Both authors read and approved the final manuscript.

\section{Competing interests}

The authors declare that they have no competing interests.

Received: 2 February 2016 Accepted: 1 April 2016

Published online: 15 April 2016

\section{References}

1. Wang N, Jiang L, Zhu B, Wen Y, Xi XM, Beijing Acute Kidney Injury Trial (BAKIT) Workgroup. Fluid balance and mortality in critically ill patients with acute kidney injury: a multicenter prospective epidemiological study. Crit Care. 2015;19:371.

2. KDIGO AKI Work Group. KDIGO clinical practice guideline for actue kidney injury. Kidney Int Suppl. 2012;(17):1-138.

3. Závada J, Hoste E, Cartin-Ceba R, Calzavacca P, Gajic O, Clermont G, et al. A comparison of three methods to estimate baseline creatinine for RIFLE classification. Nephrol Dial Transplant. 2010;25:3911-8.

4. Chevret S, Seaman S, Resche-Rigon M. Multiple imputation: a mature approach to dealing with missing data. Intensive Care Med. 2015;41:348-50.

5. Siew ED, Peterson JF, Eden SK, Moons KG, Ikizler TA, Matheny ME. Use of multiple imputation method to improve estimation of missing baseline serum creatinine in acute kidney injury research. Clin J Am Soc Nephrol. 2013;8:10-8

6. Luo X, Jiang L, Du B, Wen $Y$, Wang $M, X i X$, et al. A comparison of different diagnostic criteria of acute kidney injury in critically ill patients. Crit Care. 2014;18:R144.

7. Little RJA, Rubin DB. Statistical Analysis with Missing Data. 2nd ed. Hoboken, New Jersey: Whiley-InterScience; 2002.
Submit your next manuscript to BioMed Central and we will help you at every step:

- We accept pre-submission inquiries

- Our selector tool helps you to find the most relevant journal

- We provide round the clock customer support

- Convenient online submission

- Thorough peer review

- Inclusion in PubMed and all major indexing services

- Maximum visibility for your research

Submit your manuscript at www.biomedcentral.com/submit 